\title{
Transcription factor 4 gene rs9960767 polymorphism in bipolar disorder
}

\author{
MAVI DENIZ OZEL ${ }^{1}$, MEHMET EMIN ONDER $^{2}$ and ALI SAZCI ${ }^{3}$ \\ ${ }^{1}$ Department of Medical Biology, International School of Medicine, Istanbul Medipol University, \\ Istanbul 34810; Departments of ${ }^{2}$ Psychiatry and ${ }^{3}$ Medical Biology and Genetics, \\ Faculty of Medicine, University of Kocaeli, Kocaeli 41380, Turkey
}

Received May 11, 2016; Accepted August 8, 2016

DOI: $10.3892 /$ br.2016.742

\begin{abstract}
The transcription factor 4 (TCF4) gene encodes a helix-loop-helix transcription factor protein, which initiates neuronal differentiation and is primarily expressed during nervous system development. The aim of the present study is to investigate the association of the TCF4 rs9960767 polymorphism and bipolar disorder, which is highly heritable. DNA isolation was performed on 95 patients with bipolar disorder and 108 healthy control subjects to examine the TCF4 rs9960767 polymorphism. Genotypic and allelic frequencies were determined using the polymerase chain reaction-restriction fragment length polymorphism method designed in our laboratory. Statistical analysis was performed using $\chi^{2}$ test within the $95 \%$ confidence interval. Odds ratios were calculated and Hardy-Weinberg equilibrium (HWE) was verified for all control subjects and patients. The A allele frequency was $95.8 \%$ in the patients and $94.4 \%$ in the control subjects, and $4.2 \%$ in the patients and $5.6 \%$ in the control subjects for the $\mathrm{C}$ allele. The genotype frequencies of the TCF4 gene rs9960767 variant were as follows: AA, 91.6\% and AC, 8.4\% in patients with bipolar (CC genotype was not observed in cases); AA, $89.8 \%$; AC, $9.3 \%$ and CC, $0.9 \%$ in the control subjects. No statistically significant difference was identified between the patients and control subjects $\left(\chi^{2}=0.937 ; \mathrm{P}=0.626\right)$. In addition, gender specific analysis was performed, although no significant association was found according to the gender distrubition. All patients and control subjects were in HWE $(\mathrm{P}>0.05)$. Statistical analysis of the data indicates that the TCF4 gene rs9960767 polymorphism is not an independent risk factor for bipolar disorder in the overall population or in terms of gender; however, an increased population size would improve the statistical power. Furthermore, additional gene
\end{abstract}

Correspondence to: Dr Mavi Deniz Ozel, Department of Medical Biology, International School of Medicine, Istanbul Medipol University, Istanbul 34810, Turkey

E-mail: mdozel@medipol.edu.tr

Key words: transcription factor 4 gene, bipolar disorder, polymorphism, rs9960767, single nucleotide polymorphism variants that are specifically involved in neuronal development may be analyzed for revealing the complex genetic architecture of bipolar disorder. An improved approach would be better to evaluate the TCF4 gene in a pathway specific manner due to its role as a transcription factor.

\section{Introduction}

Bipolar disorder is a polygenic, common and chronic psychiatric disorder that has a lifetime risk of $1 \%$ worldwide (1). It is also termed manic depression due to the dramatic mood changes, such as extreme mania or severe depression, that patients experience. It is usually accompanied by thinking and behavioral disturbances, and often by psychotic features, such as delusions or hallucinations. These episodic mood changes occur at an extreme level that significantly affects the individual's social and business life (2).

Studies on families and with twins have demonstrated that bipolar disorder is highly heritable. First-degree relatives of affected individiuals are associated with a 5-10-fold increased risk of bipolar disorder compared to that of the general population. The risk may increase up to the 40-70-fold in monozygous twins (2). Despite this strong familiality, identification of bipolar disorder susceptibility genes has been challenging due to the multifactorial genetic architecture of the disease. Multiple candidate genes have been proposed by linkage analysis and genome-wide association studies (GWAs) although these results have not been consistently replicated $(3,4)$.

GWAs are systematic and objective studies based on the 'common disease, common variant' hypothesis, which allow us to identify population specific and disease-associated variants (5). Attempts to identify risk genes for common disorders, such as bipolar disorder and schizophrenia in humans have began to provide important findings. It is known that schizophrenia and bipolar disorder overlap epidemiologically, symptomatically and genetically (6). A large scale GWAs demonstrated that schizophrenia and bipolar disorder patients carry the same disease-associated variants, such as in the zinc finger protein $804 \mathrm{~A}$ and calcium voltage-gated channel subunit $\alpha 1 \mathrm{C}$ (CACNA1C) genes (2).

Stefansson et al (7) combined single nucleotide polymorphism (SNP) data from various GWAs for schizophrenia and conducted a meta-analysis of the most significant associatied 
signals. The genome-wide scan results of 12,945 schizophrenia cases and 34,591 controls were analyzed. Significant associations were identified on chromosomes 6p21.3-22.1 (major histocompatibility complex, five SNPs; rs6913660, rs13219354, rs6932590, rs13211507 and rs3131296), 11q24.2 (neurogranin, rs12807809) and 18q21.2 (transcription factor 4; TCF4, rs9960767) (7). One of these risk genes, TCF4, is also involved in normal brain development and TCF4 mutations have been associated with Pitt-Hopkins syndrome, a rare developmental disorder characterized by severe motor and mental retardation (8), additionally TCF4 deletions have been identified as risk factors for autistic-like behaviours (9).

The TCF4 gene is a basic helix-loop-helix (bHLH) transcription factor, which is also known to regulate the expression of many other genes that are involved in cell differentiation, cell survival and neurodevelopment (10). These associations between TCF4 and neurodevelopmental diseases have resulted in the present evaluation of whether the rs9960767 variant of the TCF4 gene is also associated with bipolar disorder as a neuropsychiatric disorder. In the present study, the allele and genotype frequencies of the TCF4 gene rs9960767 variant were analyzed in 95 bipolar disorder patients and 108 healthy control subjects from a Turkish population using polymerase chain reaction-restriction fragment length polymorphism (PCR-RFLP) analysis. For this method, the PCR primers were designed by the present authors and a suitable restriction enzyme was selected for analysis of the polymorphic gene site. The primers and enzyme may be used for further investigations of this particular SNP (rs9960767).

\section{Materials and methods}

Patients. The present study involved 95 patients with bipolar disorder [55 females and 40 males; aged 21-75 years (mean age, 38 years)] and 108 voluntary healthy controls [62 females and 46 males; aged 19-72 years (mean age, 36 years)] were included. All subjects were recruited from the Department of Psychiatry, Faculty of Medicine, University of Kocaeli (Kocaeli, Turkey) and diagnosis of the bipolar patients was based on the criteria of the Diagnostic and Statistical Manual of Mental Disorders. All subjects provided written informed consent and the Institutional Review Board approved the study.

Genotyping. Genomic DNA was isolated from all subjects according to the conventional salting-out method (11). Genotype and allele frequencies for the TCF4 rs9960767 variant were analyzed using a PCR-RFLP method designed in our laboratory. Forward and reverse primers, which cover the polymorphic site were designed in the present study and purchased from Integrated DNA Technologies (Coralville, IA, USA). The 264-bp fragment was amplified with 10 pmol each of the forward primer 5'-AACACTGAGTGAGGGGATCG-3' and the reverse primer 5'-GGCTTTTGAAGGGCACTGTA-3'. The PCR reaction was performed using a thermal cycler (T100; Bio-Rad Laboratories, Inc., Hercules, CA, USA). The PCR thermal conditions were as follows: Denaturation at $95^{\circ} \mathrm{C}$ for $5 \mathrm{~min}$, followed by 35 cycles of $95^{\circ} \mathrm{C}$ for $1 \mathrm{~min}, 57^{\circ} \mathrm{C}$ for $30 \mathrm{sec}, 72^{\circ} \mathrm{C}$ for $1 \mathrm{~min}$ and a final extension step at $72^{\circ} \mathrm{C}$ for $10 \mathrm{~min}$. The digestion of the amplified 264-bp fragment with the ApoI restriction endonuclease was conducted at $37^{\circ} \mathrm{C}$ overnight. Digestion fragments were electrophoresed at $20 \mathrm{~W}$ for $40 \mathrm{~min}$ on an $8 \%$ polyacrylamide gel, subsequently Silver Staining was conducted and scanning was performed using a CanoScan N670U (Canon, Inc., Tokyo, Japan). The ApoI digestion of the PCR product produced 193- and 71-bp fragments for the CC genotype, 177-, 71- and 16-bp fragments for the AA genotype and 193-, 177-, 71- and 16-bp fragments for the AC genotype (Fig. 1).

Statistical analysis. The Hardy-Weinberg equilibrium (HWE) was verified for the two groups. Statistical analyses were performed using the SPSS software package, version 21.0 (IBM SPSS, Armonk, NY, USA). Allelic distributions and genotype frequencies were compared using the $\chi^{2}$ test and Student's t-test. The relative risk (odds ratio; OR) analysis was performed with $2 \times 2$ crosstabulation and binary logistic regression model for gender. $\mathrm{P}<0.05$ was considered to indicate a statistically significant difference.

\section{Results}

TCF4 gene rs9960767 allele and genotype frequencies were analyzed for 95 bipolar disorder patients and 108 healthy control subjects. A allele frequencies were $95.8 \%$ in the patients and $94.4 \%$ in the control subjects. The genotype frequencies of the TCF4 gene rs9960767 variant were as follows: AA, 91.6\% and $\mathrm{AC}, 8.4 \%$ in the patients (the $\mathrm{CC}$ genotype was not observed in the patients); AA, 89.8\%; AC, 9.3\% and CC, $0.9 \%$ in the control subjects. No statistically significant association was identified between the patients and the control subjects $\left(\chi^{2}=0.937 ; \mathrm{P}=0.626\right)$. Gender specific statistical analysis was also performed, however, no significant association was identified according to the gender distrubition. All cases and controls were in HWE ( $\mathrm{P}>0.05$; Table I).

\section{Discussion}

It is known that bipolar disorder (also termed manic depression) is strongly influenced by genetic factors (12). It is a common, complex and polygenic disease that shows multifactorial inheritance. There are numerous methods that have been developed to investigate complex disorders. One of the most promising methods is with GWA, due to the power of identifying the common genetic variants that are involved in major complex disorders, such as schizophrenia and bipolar disorder (13). The genetic and symptomatic overlaps between these disorders resulted in the examination of mutual variants in the present study. Stefansson et al (7) found a significant association with various polymorphisms in a large GWA study. The samples were as follows: European samples, 2,663 schizophrenia patients and 13,498 control subjects (SGENE-plus samples); European follow-up samples, 4,999 schizophrenia patients and 15,555 control subjects; and 5,283 schizophrenia patients and 5,088 control subjects from the International Schizophrenia Consortium and the Molecular Genetics of Schizophrenia study. TCF4 gene rs9960767 is one of the risk variants and was found to be more frequent in patients with schizophrenia $[\mathrm{P}=4.1 \times 10-9 ; \mathrm{OR}=1.23,95 \%$ confidence interval $(\mathrm{CI})=1.15-1.32]$. This association was further confirmed in a 
A

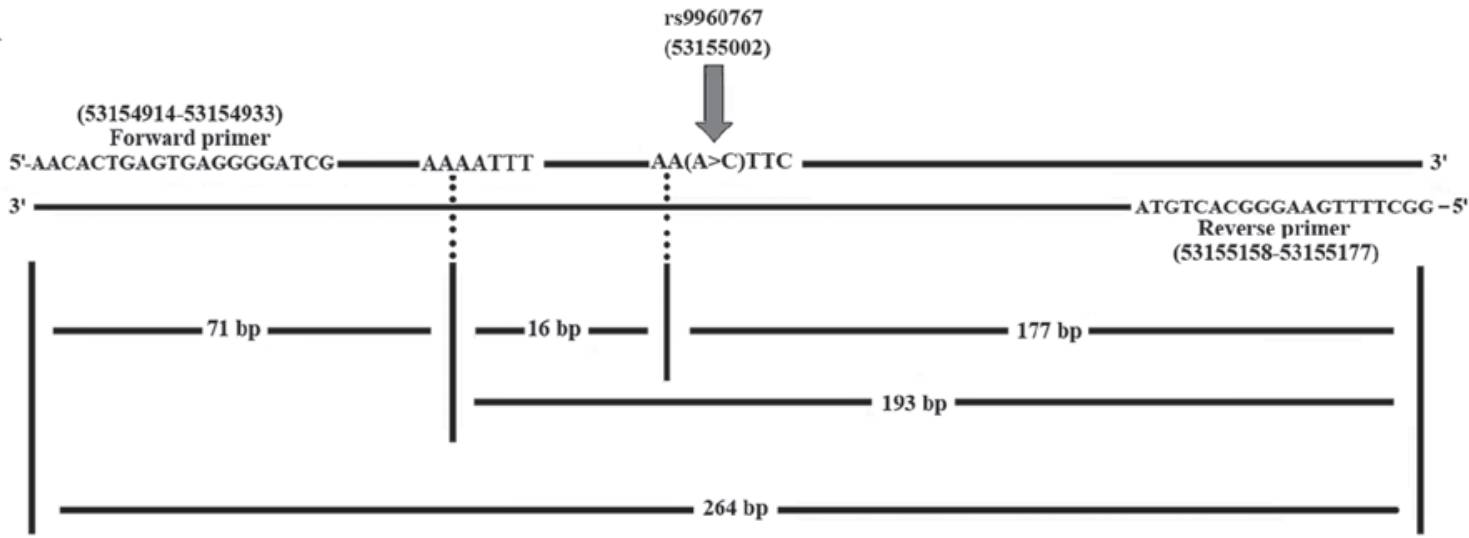

B

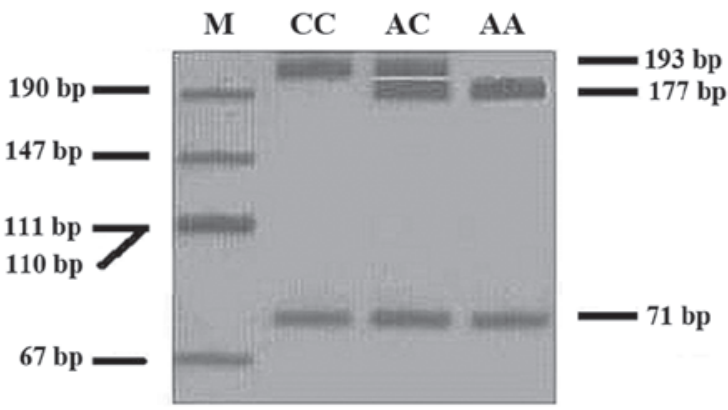

Figure 1. (A) Schematic of the TCF4 gene demonstrating the location of the ApoI recognition sequences (5' ...R/AATTY...3') relative to the primer annealing sites (Genomic Reference Consortium: GRCh37.p13). Forward and reverse primers shown on the gene produce a 264-bp fragment of which there is always an ApoI restriction site at position 53154985, which produces two fragments of length 193 and $71 \mathrm{bp}$. Another ApoI restriction site created upon the transversion of C to A base at position 53155002 produces three fragments of 177, 71 and $16 \mathrm{bp}$. (B) Polyacrylamide gel electrophoresis image of the TCF4 rs9960767 gene. Lane M, marker; lane CC, CC genotype with two fragments of length 193 and 71 bp; lane AC, AC genotype with fragments of length 193, 177 and 71 bp (with the exception of the 16-bp fragment due to the long duration of electrophoresis); lane AA, AA genotype with fragments of length 177 and 71 bp (with the exception of the 16-bp fragment due to the long duration of electrophoresis). TCF4, transcription factor 4.

Table I. Allele and genotype frequencies of the TCF4 gene rs9960767 polymorphism in patients with bipolar disorder and control subjects.

\begin{tabular}{lccccc}
\hline Gene & Cases, $\mathrm{n}(\%)$ & Controls, $\mathrm{n}(\%)$ & $\chi^{2}$ & P-value & OR; 95\% CI \\
\hline TCF4 (rs9960767) & $95(100.0)$ & $108(100.0)$ & 0.937 & 0.626 & \\
AA & $87(91.6)$ & $97(89.8)$ & 0.185 & 0.667 & $1,233(0,474-3,207)$ \\
CC & $0(-)$ & $1(0.9)$ & 0.884 & 0.347 & - \\
AC & $8(8.4)$ & $10(9.3)$ & 0.044 & 0.834 & $0,901(0,340-2,385)$ \\
Allele frequency & & & & & - \\
A allele & $(95.8)$ & $(94.4)$ & 0.884 & 0.347 & $0.811(0.312-2.108)$ \\
C allele & $(4.2)$ & $(5.6)$ & 0.185 & 0.667 & \\
HWE exact (P-value) & 1.000 & 0.275 & & & \\
\hline
\end{tabular}

HWE, hardy-weinberg equilibrium; OR, odds ratio; CI, confidence interval; TCF4, transcription factor 4.

large-scale meta-analysis of schizophrenia GWAs $\left(\mathrm{P}=4.2 \times 10^{-9}\right.$; $\mathrm{OR}=1.20,95 \% \mathrm{CI}=1.13-1.27)(14)$.

TCF4 gene (also termed immunoglobulin transcription factor 2) is located on chromosome 18q21.2. This gene encodes a bHLH transcription factor, which recognizes a 5'-CANNTG-3' motif in Ephrussi-box (E-box) found in immunoglobluin enhancers. TCF4 binding activates transcription in E-box. TCF4 is expressed in the nervous system and initiates neuronal differantiation. Multiple alternatively spliced transcipt variants have been described that encode different proteins. rs9960767 is an intronic variant found in the TCF4 gene that results in $\mathrm{A}>\mathrm{C}$ transversion (dbSNP). Li et al (15) attempted to investigate nine polymorphisms in a large Han Chinese population; four of the SNPs were not identified to be polymorphic in the Han Chinese population, which is consistent with the HapMap data. The authors genotyped 2,496 schizophrenia patients and 5,184 control subjects, however, did not find any A $>C$ transversion even in a single sample for rs9960767 (15). 
There are numerous cognitive-based studies evaluating the association between cognitive performance and the TCF4 genotype in psychiatric disorders. Lennertz et al (16) investigated the correlation between neurocognitive functions and schizophrenia. In total, 401 schizophrenia patients were genotyped for TCF4 rs9960767 and the Rey Auditory Verbal Learning Test was performed with all subjects. No significant difference for verbal memory was identified between the AA genotype and $\mathrm{C}$ risk allele carrier subjects although the $\mathrm{C}$ risk allele carriers performed better than the non-carriers in recognition memory $(\mathrm{P}=0.049)$ (16). Quednow et al (17) performed a sensorimotor gating analysis in cases of schizophrenia and healthy control subjects. The TCF4 genotype was found to modulate sensorimotor gating, which was reduced in C risk allele carriers (17). Albanna et al (18) genotyped TCF4 rs9960767 in 173 patients with first-episode psychosis. Cognitive tests were also performed on all subjects. AA carriers showed improved performance $(\mathrm{P}=0.038)$ in problem solving and reasoning compared with the $\mathrm{C}$ risk allele carriers (CC/CA) (18). These studies demonstrated that TCF4 may influence cognitive function and contribute to psychiatric disorders.

TCF4 variations are known to be involved in a rare neurodevelopmental disease termed Pitt-Hopkins syndrome, which shows an autosomal dominant transmission and is charactarized by developmental delay, typical facial features, and severe mental and motor retardation (19). A translocation that contains exon four of the TCF4 gene was also found to be associated with milder mental retardation when compared with patients with Pitt-Hopkins syndrome (20).

The TCF4 gene is associated with schizophrenia, a common disease and Pitt-Hopkins syndrome, which is rare. It interacts with other genes and forms a transcriptional network to regulate differentiation in various cell types. The TCF4 gene has been identified as a target for the microRNA 137 (miR137) gene product, miRNA137, which is asociated with schizophrenia and severe cognitive abnormalities (21). miR137 is involved in neurogenesis and neuronal differentiation. Specific software programmes, such as TargetScan (22) and PicTar (23), were used to analyze the targets of miR137, and four genes (TCF4, CACNA1C, CUB and Sushi multiple domains 1 and WW domain binding protein 1-like) were detected in the study by the Schizophrenia Psychiatric GWAS Consortium (24). Overexpression or knockdown of the miR137 gene also affect expression of the TCF4 gene that confirmed the association between TCF4 and miR137 (25).

Although the TCF4 rs9960767 variant is in an intronic region, it may affect transcriptional regulation. It remains unclear how the TCF4 gene is involved in psychiatric disorders, although its role in neuronal differantiation may be an indication of the pathogenesis of neuropsychiatric diseases. Population size is important, particularly in case-control studies, for increasing statistical power. In the present study, a $\mathrm{CC}$ genotype was not available, which was due to the relatively small population size.

In conclusion, this is the first study, to the best of our knowledge, to investigate the association between the TCF4 gene rs9960767 variant and bipolar disorder. It was found that the TCF4 gene rs9960767 was not a genetic risk factor for bipolar disorder in the Turkish population that was evaluated. Neither allelic, nor genotypic associations have been found in overall population or in terms of gender. Larger populations may be required for corroboration of these study findings. Further genetic, biological and cognitive studies are required to better understand the complex mechanisms underlying the effect of TCF4 on neural functions with regard to psychiatric diseases.

\section{Acknowledgements}

The present study was supported by Kocaeli University (Kocaeli, Turkey; grant no. 2011/68).

\section{References}

1. Craddock N, O'Donovan MC and Owen MJ: The genetics of schizophrenia and bipolar disorder: dissecting psychosis. J Med Genet 42: 193-204, 2005.

2. Craddock N and Sklar P: Genetics of bipolar disorder. Lancet 381: 1654-1662, 2013

3. Hou L, Bergen SE, Akula N, Song J, Hultman CM, Landén M, Adli M, Alda M, Ardau R, Arias B, et al: Genome-wide association study of 40,000 individuals identifies two novel loci associated with bipolar disorder. Hum Mol Genet: Jun 21, 2016 (Epub ahead of print).

4. Kao CF, Chen HW, Chen HC, Yang JH, Huang MC, Chiu YH, Lin SK, Lee YC, Liu CM, Chuang LC, et al: Identification of susceptible loci and enriched pathways for bipolar II disorder using genome-wide association studies. Int J Neuropsychopharmacol: Aug 2, 2016 (Epub ahead of print).

5. Owen MJ, Williams HJ and O'Donovan MC: Schizophrenia genetics: Advancing on two fronts. Curr Opin Genet Dev 19: 266-270, 2009.

6. Craddock $\mathrm{N}$ and Owen MJ: The Kraepelinian dichotomy - going, going... but still not gone. Br J Psychiatry 196: 92-95, 2010.

7. Stefansson H, Ophoff RA, Steinberg S, Andreassen OA, Cichon S, Rujescu D, Werge T, Pietiläinen OP, Mors O, Mortensen PB, et al; Genetic Risk and Outcome in Psychosis (GROUP): Common variants conferring risk of schizophrenia. Nature 460: 744-747, 2009.

8. Amiel J, Rio M, de Pontual L, Redon R, Malan V, Boddaert N, Plouin P, Carter NP, Lyonnet S, Munnich A, et al: Mutations in TCF4, encoding a class I basic helix-loop-helix transcription factor, are responsible for Pitt-Hopkins syndrome, a severe epileptic encephalopathy associated with autonomic dysfunction. Am J Hum Genet 80: 988-993, 2007.

9. O'Donnell L, Soileau B, Heard P, Carter E, Sebold C, Gelfond J, Hale DE and Cody JD: Genetic determinants of autism in individuals with deletions of 18q. Hum Genet 128: 155-164, 2010.

10. Forrest MP, Waite AJ, Martin-Rendon E and Blake DJ: Knockdown of human TCF4 affects multiple signaling pathways involved in cell survival, epithelial to mesenchymal transition and neuronal differentiation. PLoS One 8: e73169, 2013.

11. Miller SA, Dykes DD and Polesky HF: A simple salting out procedure for extracting DNA from human nucleated cells. Nucleic Acids Res 16: 1215, 1988.

12. Goes FS: Genetics of bipolar disorder: recent update and future directions. Psychiatr Clin North Am 39: 139-155, 2016.

13. McCarthy MI, Abecasis GR, Cardon LR, Goldstein DB, Little J, Ioannidis JP and Hirschhorn JN: Genome-wide association studies for complex traits: consensus, uncertainty and challenges. Nat Rev Genet 9: 356-369, 2008.

14. Steinberg $\mathrm{S}$, de Jong $\mathrm{S}$, Andreassen OA, Werge $\mathrm{T}$, Børglum AD, Mors O, Mortensen PB, Gustafsson O, Costas J, Pietiläinen OP, et al; Irish Schizophrenia Genomics Consortium; GROUP; Wellcome Trust Case Control Consortium 2: Common variants at VRK2 and TCF4 conferring risk of schizophrenia. Hum Mol Genet 20: 4076-4081, 2011.

15. Li T, Li Z, Chen P, Zhao Q, Wang T, Huang K, Li J, Li Y, Liu J, Zeng Z, et al: Common variants in major histocompatibility complex region and TCF4 gene are significantly associated with schizophrenia in Han Chinese. Biol Psychiatry 68: 671-673, 2010.

16. Lennertz L, Rujescu D, Wagner M, Frommann I, Schulze-Rauschenbach S, Schuhmacher A, Landsberg MW, Franke P, Möller HJ, Wölwer W, et al: Novel schizophrenia risk gene TCF4 influences verbal learning and memory functioning in schizophrenia patients. Neuropsychobiology 63: 131-136, 2011. 
17. Quednow BB, Ettinger U, Mössner R, Rujescu D, Giegling I Collier DA, Schmechtig A, Kühn KU, Möller HJ, Maier W, et al: The schizophrenia risk allele C of the TCF4 rs9960767 polymorphism disrupts sensorimotor gating in schizophrenia spectrum and healthy volunteers. J Neurosci 31: 6684-6691, 2011

18. Albanna A, Choudhry Z, Harvey PO, Fathalli F, Cassidy C, Sengupta SM, Iyer SN, Rho A, Lepage M, Malla A, et al: TCF4 gene polymorphism and cognitive performance in patients with first episode psychosis. Schizophr Res 152: 124-129, 2014.

19. Sepp M, Pruunsild P and Timmusk T: Pitt-Hopkins syndrome-associated mutations in TCF4 lead to variable impairment of the transcription factor function ranging from hypomorphic to dominant-negative effects. Hum Mol Genet 21: 2873-2888, 2012.

20. Kalscheuer VM, Feenstra I, Van Ravenswaaij-Arts CM, Smeets DF, Menzel C, Ullmann R, Musante L and Ropers HH: Disruption of the TCF4 gene in a girl with mental retardation but without the classical Pitt-Hopkins syndrome. Am J Med Genet A 146A: 2053-2059, 2008.

21. Siegert S, Seo J, Kwon EJ, Rudenko A, Cho S, Wang W, Flood Z, Martorell AJ, Ericsson M, Mungenast AE, et al: The schizophrenia risk gene product miR-137 alters presynaptic plasticity. Nat Neurosci 18: 1008-1016, 2015.
22. Lewis BP, Burge CB and Bartel DP: Conserved seed pairing, often flanked by adenosines, indicates that thousands of human genes are microRNA targets. Cell 120: 15-20, 2005.

23. Krek A, Grün D, Poy MN, Wolf R, Rosenberg L, Epstein EJ, MacMenamin P, da Piedade I, Gunsalus KC, Stoffel M, et al: Combinatorial microRNA target predictions. Nat Genet 37: 495-500, 2005.

24. Schizophrenia Psychiatric Genome-Wide Association Study (GWAS) Consortium: Genome-wide association study identifies five new schizophrenia loci. Nat Genet 43: 969-976, 2011.

25. Ripke S, O'Dushlaine C, Chambert K, Moran JL, Kähler AK, Akterin S, Bergen SE, Collins AL, Crowley JJ, Fromer M, et al; Multicenter Genetic Studies of Schizophrenia Consortium; Psychosis Endophenotypes International Consortium; Wellcome Trust Case Control Consortium 2: Genome-wide association analysis identifies 13 new risk loci for schizophrenia. Nat Genet 45: 1150-1159, 2013. 